\title{
INFLUENCE OF MINERAL COMPOSITION IN NATURAL GRANITE ROCKS ON MICROHARDNESS
}

\author{
ESZTER KeLEMEN-CSERTA*1 AND ISTVÁN GÁBOR GYURIKA ${ }^{1}$ \\ ${ }^{1}$ Research Centre for Engineering Sciences, University of Pannonia, Egyetem u. 10, 8200 Veszprém, \\ HUNGARY
}

\begin{abstract}
Granites are becoming increasingly popular and, as a result, their areas of use are expanding. In addition to their colour and particle size, the surface roughness of the machined material is becoming an important aspect of their application. In order to create a suitable surface roughness, the type of rocks located on the surface, elemental composition and microhardness of the minerals are important, because knowledge of these characteristics can be used to determine the machining parameters. Microhardness is affected by the atomic percentage values of $\mathrm{Si}, \mathrm{Al}$ and $\mathrm{Na}$. In addition, for some minerals, a correlation can also be established between the $\mathrm{Si}, \mathrm{Al}$ and $\mathrm{Na}$ components.
\end{abstract}

Keywords: natural rocks, granite, microhardness, surface roughness

\section{Introduction}

Granites are one of the most commonly used natural rocks due to their beautiful appearance and the fact that many variations in their colour can be found. Their appearance is special since the grains of the constituent minerals found in granite are nicely outlined and clearly visible with the naked eye, therefore, are also preferred architecturally. Zhao et al. [1] studied the effect of weathering on samples of granite. For this purpose, the samples were soaked in different concentrations of $\mathrm{Na}_{2} \mathrm{SO}_{4}$ and $\mathrm{MgSO}_{4}$ before the wetting-drying cycles. It was found that the increase in wetting-drying cycles greatly influences the physical parameters, namely weight, colour, surface roughness and hardness. In addition, the effect of $\mathrm{Na}_{2} \mathrm{SO}_{4}$ on the specimens was greater than that of $\mathrm{MgSO}_{4}$ and the higher salt concentration accelerated weathering of the rock.

Although the spectacular grain structure of granite is advantageous in terms of appearance, it is disadvantageous in terms of machinability. The particles are composed of different minerals that result in a heterogeneous structure. This heterogeneous property makes machining difficult.

Ramnath et al. [2] have developed epoxy granite composites (EGCs) as a novel alternative material, which exhibit several positive properties, e.g., are stable and lighter, but due to their heterogeneous structure, machining was critical. According to experiments, it was shown that $600 \mathrm{rpm}$ is the optimal spindle speed and $0.09 \mathrm{~m} / \mathrm{min}$ is the optimal feed rate for machining this material. This

\footnotetext{
*Correspondence: kelemen.cserta.eszter@mk.uni-pannon.hu
}

value can even be used for natural granite rocks.

In collaboration with us, many researchers have studied the formation, change and effect of surface roughness. Sanmartín et al. [3] studied the effect of surface treatment on roughness, surface gloss and colour. It was found that the colour of granite affects the gloss of the surface differently for smooth and rough surfaces. The change in luminosity also depends on the mineral composition of the rock.

Shen et al. [4] studied concrete and granite by investigating the relationship between surface roughness and hydrophilicity. In their experiments, it was observed that the bonding strength always increases with the joint roughness coefficient (JRC). Furthermore, the relationship between surface roughness and hydrophilicity was determined as well as the importance of knowing the effect of surface adhesion and surface characteristics evaluated.

Aydin et al. [5] machined the surface of granite rocks with diamond saw blades and examined their surface roughness. They concluded that instead of mechanical properties, mineral properties affect surface roughness. Among the mineralogical properties, the particle size was chosen as the primary aspect of surface roughness.

Others have studied the hardness of granite from different perspectives. Prikryl [6] cut thin sections of the rock samples in which the size, distribution, shape, orientation and mineral composition of the grains were analysed. It was found that as the particle size of minerals decreases, their strength increases.

Rajpurohit et al. [7] investigated a statistical relationship between the Cerchar Hardness Index and this dia- 
mond tool. It was concluded that the hardness of the rock greatly influences the wear of the tool. A similar result was obtained by Delgado et al. [8] who studied the sawability of granite as well as determined that its hardness strongly influences the sawability and wear of diamond tools. The Vickers hardness of minerals was measured experimentally and it was determined that a small increase in hardness leads to a large decrease in the sawing speed. A similar result was obtained by Dong et al. [9] who developed an innovative method for sawing hard rocks and demonstrated that the sawing force correlates with the properties of the rock.

A similar experiment was performed by Yilmaz [10], who examined the wear of diamond tools as a function of the hardness of the minerals that granite is composed of. The rock hardness index of the specimens was used to determine the hardness according to the percentage occurrence of the constituent minerals. The results showed that the rock hardness index correlated with the sawblade wear rate (SWR) of the tool. Even though previous studies have attributed the percentage occurrence of quartz to the main reason for sawblade wear, Yilmaz's results showed that other minerals also influence tool wear. In another study, where Yilmaz et al. [11] conducted experiments on natural granite, they found that the maximum particle size of quartz, orthoclase and microcline had the greatest effect on SWR.

Li et al. [12] studied how the mineral content of rock affects its properties. For this purpose, the mineral content, particle size, abrasion resistance and hardness of 96 samples from 10 provinces in China were measured. The test results showed that the wear and hardness of the rock can be accurately determined based on the type of rock, mineral content and particle size.

Diamond is extremely hard, tough and thermally conductive, making it an excellent material for the purpose of cutting rocks. The abrasion resistance of rocks varies, so it is important to provide the right metal matrix in which the diamond grains can be placed. During the experiment, 2 materials were investigated, that is, the $\mathrm{Co}-$ and $\mathrm{Fe}$ based metal matrices. The results showed that the Cobased metal matrix is suitable for cutting granites, while the Fe-based one is suitable for cutting marbles [13]. This theory is also supported according to a study by Gupta and Pratap [14]. They also studied the metal matrix of the tool and found that the metal matrix composite (MMC) influences the efficiency and service life of the tool.

Yan et al. [15] also searched for a way of modifying the machining tool to ensure granite surfaces are properly machined. An ultrahard polycrystalline diamond (UHPCD) tool was compared to a polycrystalline diamond (PCD) one. The hardness of UHPCD was 105-115 GPa, while that of PCD was 53-57 GPa. The results showed that the lifetime of UHPCD bits was $132.33 \mathrm{~m}$ and that of PCD ones was $83.76 \mathrm{~m}$.

Using a hammer, Adebayo and Okewale [16] determined the rebound values of the specimens as a function of hardness as well as the mineral compositions of the samples. It was concluded that the sample with the highest quartz content resulted in the highest Vickers hardness number.

A document published by the University of Kiel [17] contains a table presenting the Vickers hardness number of several materials, in which the Vickers hardness number of granite is $H_{\mathrm{Vgranite}}=850$ and that of quartz is $H_{\text {Vquartz }}=1200$.

Yusupov and co-researchers [18] studied the hardness of minerals in terms of grindability. It was concluded that the presence of quartz increases the grinding time by 1.52 times. To optimize the process and reduce the amount of energy required, they proposed a method in which the minerals are machined separately.

Xie and Tamaki [19] investigated the effect of the micro-hardness distribution in granite on the efficiency of abrasive machining. In their research, it was determined that the efficiency of abrasive machining increases as the microhardness of granite decreases.

From the literature, it is also clear that researchers have considered the types of minerals when studying natural rocks. In contrast, in the present paper, the mineral constituents are examined to observe how these affect the hardness of specimens and thus their machinability.

Our goal is to draw up a prediction system based on complex analysis to facilitate the specification of the parameters required for surface machining. Alternatively, the parameters can be modified according to the types of minerals present on the surface or the quality of the surface to be created.

\section{Materials and methods}

The granites used in the experiments differ in terms of colour (pink, yellowish, orange, greyish, black and white), grain size (fine, medium and coarse) and composition. 4 of the 5 samples come from Brazil and 1 from the Hungarian mine in Süttő.

During the experiment, an experimental process was developed to investigate the composition, formation and hardness of the rock. It was determined that although all granite samples contained the minerals quartz, feldspar and biotite, the difference was in the type of feldspar minerals.

\subsection{Rock working}

The surface of the slabs composed of natural rock was machined by a CNC machine manufactured in Italy (Fig. 1). The used equipment was an Italian Prussiani Golden Plus-type CNC machine with a maximum power consumption of $15 \mathrm{~kW}$. The machining cutting depth was 1 $\mathrm{mm}$, the cutting width was $40 \mathrm{~mm}$ and the feed speed was $0.1 \mathrm{~mm} /$ tooth. The cutting speed used during machining was $37.7 \mathrm{~m} / \mathrm{min}$. The machining tool in the CNC machine consisted of 22 segments and the face mill was $100 \mathrm{~mm}$ in diameter. Although the elemental composition of the face-mill matrix is not specified by the manufacturers, 


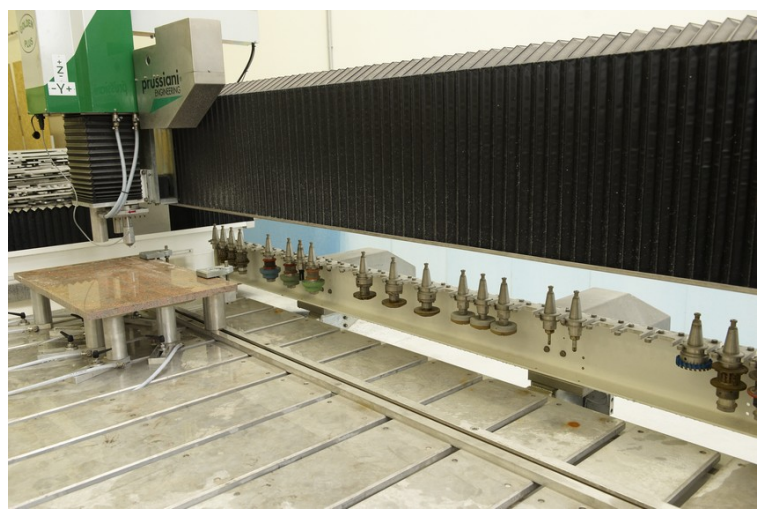

Figure 1: The CNC equipment and various tools

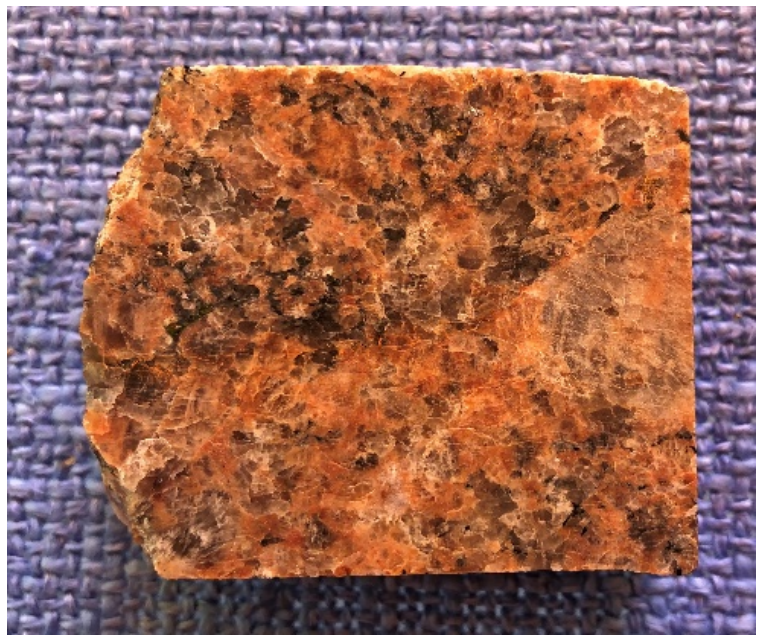

Figure 2: One of the granite samples (orange)

scanning electron microscopy (SEM) of the tool showed that $\mathrm{Co}, \mathrm{Cu}, \mathrm{Sn}$ and $\mathrm{Ag}$ were also present.

\subsection{Hardness measurements}

Samples with approximate dimensions of $5 \mathrm{~mm} \times 5 \mathrm{~mm}$ (Fig. 2) were cut from the machined rock slabs to ensure that they could be easily placed on the tables of various measuring devices.

The minerals were separated based on their appearance. Biotite, which could be identified by its characteristic dark/black colour, was the first to be examined, followed by feldspar and quartz. In the case of the latter two, even though it was more difficult to distinguish them from each other, in the following examination of mineral composition, it was possible to make an accurate distinction between them.

The hardness of minerals is usually given according to the Mohs scale. This does not provide an exact value, rather only reflects the relative hardness of the different minerals.

Secondly, it is worth mentioning the methods used to measure the hardness of metals, which despite yielding accurate values, are greatly influenced by different compositions of minerals.
Table 1: Parameters of the Wolpert Group hardness tester

\begin{tabular}{ll}
\hline Eyepiece magnification & $10 \times$ \\
Resolution & $0.1 \mu \mathrm{m}$ \\
Objective magnification factor & $10 \times, 20 \times, 40 \times, 50 \times, 60 \times$ \\
Total magnification & $400 \times$ (for measurements) \\
& $100 \times$ (for observations) \\
Measuring range & $200 \mu \mathrm{m}$ \\
Hardness value & 5 -digit \\
Maximum specimen height & $85 \mathrm{~mm}$ \\
XY stage dimensions & $100 \times 100 \mathrm{~mm}$ \\
Operating temperature & Range: 10 to $38^{\circ} \mathrm{C}$ \\
& $\left(50\right.$ to $\left.100{ }^{\circ} \mathrm{F}\right)$ \\
\hline
\end{tabular}

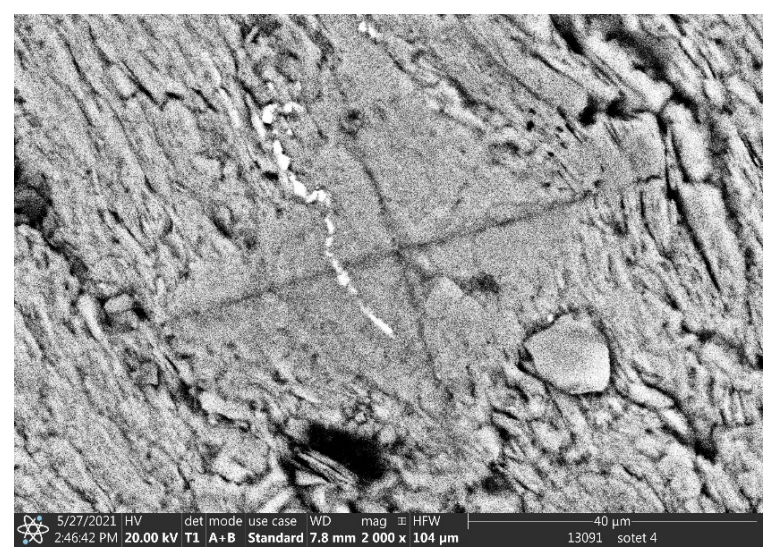

Figure 3: Imprint of the $136^{\circ}$ square-based diamond pyramid

Measurements were performed on a WOLPERT W Group Micro Vickers digital auto turret 402MVD-type hardness tester, the parameters of which are shown in Table 1 .

When measurements were taken, a specimen was placed on the measuring table and then the $136^{\circ}$ squarebased diamond pyramid for measuring the Vickers hardness was placed over the relevant mineral. After starting to take the measurements, the pyramid was pressed into the surface of the mineral where it left an imprint (Fig. 3 ). The peaks of the imprint were marked using a microscope, before the machine evaluated the results.

\subsection{SEM}

The chemical composition can be determined by scanning electron microscopy (SEM). A Thermo Fischer Scientific Aprea SEM, FEI/Philips XL-30 ESEM were used to examine the elemental composition of the sample's surface in a low vacuum at a resolution of $20 \AA$. During the evaluation, the equipment took a photo of the surface before evaluating the compositions of the selected areas. Given that the results were given in percentage composition, the types of constituent minerals present could be deduced (Fig. 4). 


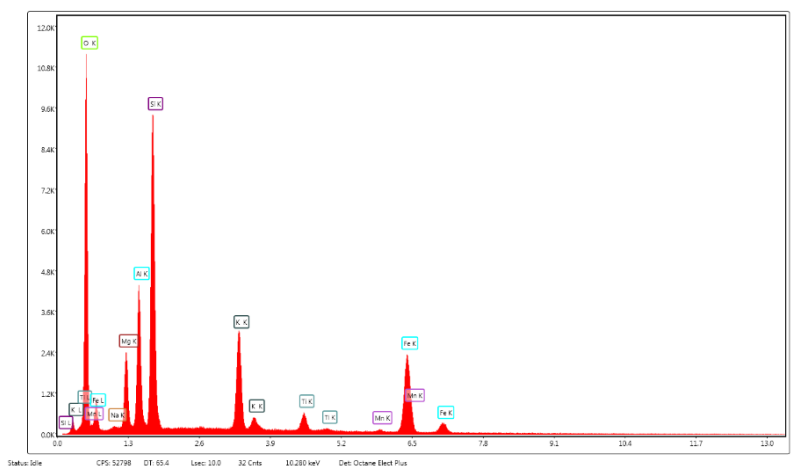

Figure 4: Elemental composition of biotite

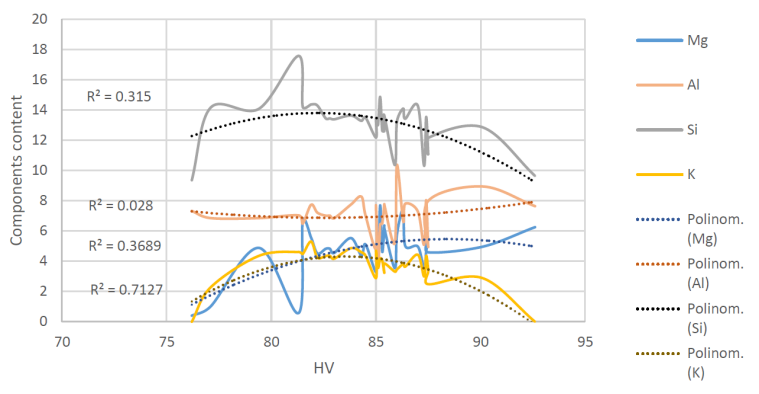

Figure 5: Effect of $\mathrm{Mg}, \mathrm{Al}, \mathrm{Si}$ and $\mathrm{K}$ constituents on Vickers hardness

\section{Results}

During this study, the minerals biotite, feldspar and quartz were examined on the surfaces of 5 different specimens.

Firstly, biotite was placed under the diamond pyramid of the hardness tester. It is known that the content of $\mathrm{SiO}_{2}$ and grain size greatly influence the hardness as well as machinability of the specimens. However, it has not yet been studied whether and how the atomic percentage composition of the particles affects the hardness. Given that the hardness of granites is related to their quartz content, it was examined whether the hardness varies as a function of the Si content. Our measurements showed no correlation between the values. For biotite, no correlation was found between Si content and Vickers hardness.

Additional measurements also showed that the atomic percentage composition of biotite did not correlate with the Vickers hardness (HV). During the evaluation, the constituent elements $(\mathrm{Mg}, \mathrm{Al}, \mathrm{K})$ were examined separately, but no correlation $\left(R_{\mathrm{Mg}}^{2}=0.315, R_{\mathrm{Al}}^{2}=\right.$ $0.028, R_{\mathrm{Si}}^{2}=0.3689, R_{\mathrm{K}}^{2}=0.6127$ where $R^{2}$ denotes the coefficient of determination) was found between changes in any of these constituents and hardness. It is also clear from the diagram (Fig. 5) that the individual constituents do not affect the Vickers hardness.

The next group of minerals studied were feldspars. After evaluating the measurements, several correlations were observed. Given that as the Si content increases, the total content of $\mathrm{Na}$ and $\mathrm{Al}$ decreases (Fig. 6), it can be stated that a decrease in the Si content leads to an increase

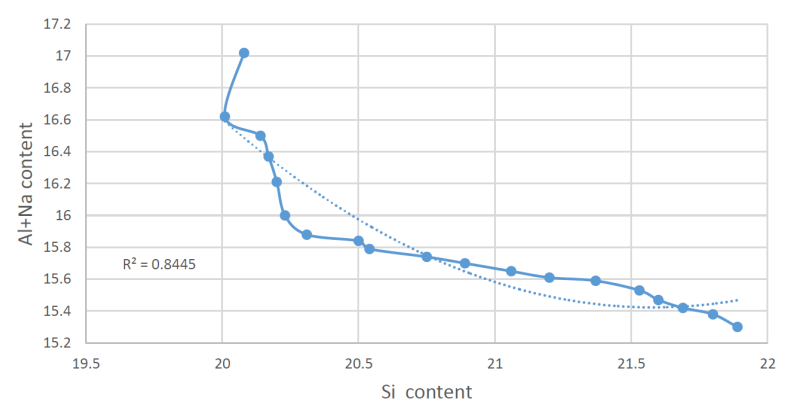

Figure 6: The correlation between $\mathrm{Na}+\mathrm{Al}$ and $\mathrm{Si}$ contents

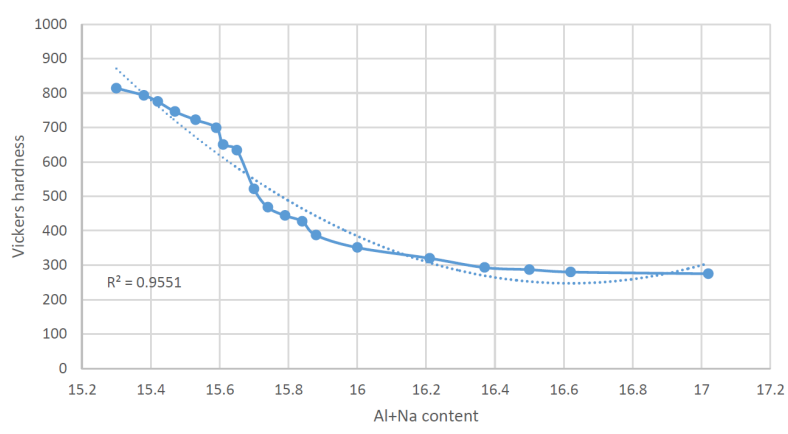

Figure 7: The correlation between $\mathrm{HV}$ and $\mathrm{Na}+\mathrm{Al}$ content

in the $\mathrm{Na}+\mathrm{Al}$ content in the case of feldspars $\left(R_{\mathrm{Al}+\mathrm{Na}}^{2}=\right.$ $0.8445)$.

It also greatly affects the Vickers hardness. The change in Vickers hardness is inversely proportional to an increase in $\mathrm{Na}+\mathrm{Al}$ content (Fig. 7). As the $\mathrm{Na}+\mathrm{Al}$ content in the mineral increases, the Vickers hardness decreases $\left(R_{\mathrm{HV}}^{2}=0.9551\right)$.

The results of our measurements are illustrated in the diagram Fig. 7.

In the case of the mineral quartz, the results do not exhibit such a correlation $\left.R_{\mathrm{HV}}^{2}=0.2646\right)$. In uncontaminated quartz, where no impurities $(\mathrm{C}, \mathrm{K}, \mathrm{Ca}, \mathrm{Fe})$ were detected, large variations in hardness were observed (Fig. 8), presumably due to the crystallization of quartz.

For minerals where other constituents are present in addition to quartz, neither were clear correlations between the changes in Vickers hardness and elemental composition observed. Given the results, changes in the constituents of quartz do not affect the Vickers hardness.

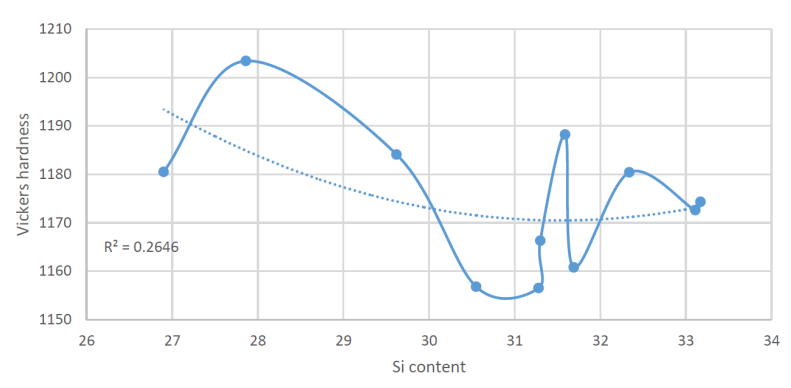

Figure 8: The correlation between HV and Si content 


\section{Conclusions}

An important aspect when machining natural rocks is the hardness of the minerals they are composed of, because the hardness of the rock surface greatly influences machinability. Based on preliminary measurements, the surface composition of feldspars was examined in order to predict their hardness.

With the knowledge obtained during the present study, the parameters of the processing equipment can be adjusted according to the mineral composition on the given surface.

In the case of the minerals biotite and quartz, clear values for machining could not be provided, since increasing the Si content of either mineral has no effect on the Vickers hardness.

Our results suggest that $\mathrm{Na}+\mathrm{Al}$ constituents do not affect either the change in hardness or the Si content.

In the case of feldspars, on the other hand, it was observed that both the hardness and Si content are inversely proportional to the $\mathrm{Na}+\mathrm{Al}$ content. As granites constitute several types of feldspars, these research results are a major step forward in the development of a forecasting system.

\section{Acknowledgements}

The authors are deeply indebted to their supervisor Dr. Margit Eniszné Bódogh (PhD; University of Pannonia), Ferencné Bakos (laboratory technician, University of Pannonia) and Miklós Jakab (PhD student, University of Pannonia) for their help in the measurement and evaluation processes applied in the scope of the present study.

\section{REFERENCES}

[1] Zhao, F.; Sun, Q.; Zhang, W.: Combined effects of salts and wetting-drying cycles on granite weathering, Bull. Eng. Geol. Environ., 2020, 79(7) 37073720 DOI: 10.1007/s10064-020-01773-3

[2] Arun Ramnath, R.; Thyla, P. R.; Harishsharran, A. K. R.: Machining parameter selection in milling epoxy granite composites based on AHP, Mater. Today Proc., 2021, 42(2), 319-324 DOI: 10.1016/j.matpr.2020.09.340

[3] Sanmartín, P.; Silva, B.; Prieto, B.: Effect of surface finish on roughness, color, and gloss of ornamental granites, J. Mater. Civ. Eng., 2011, 23(8), 12391248 DOI: 10.1061/(ASCE)MT.1943-5533.0000285

[4] Shen, Y.; Wang, Y.; Yang, Y.; Sun, Q.; Luo, T.; Zhang, H.: Influence of surface roughness and hydrophilicity on bonding strength of concrete-rock interface, Constr. Build. Mater., 2019, 213, 156-166 DOI: 10.1016/j.conbuildmat.2019.04.078

[5] Aydin, G.; Karakurt, I.; Aydiner, K.: Investigation of the surface roughness of rocks sawn by diamond sawblades, Int. J. Rock Mech. Min. Sci., 2013, 61, 171-182 DOI: 10.1016/j.ijrmms.2013.03.002
[6] Prikryl, R.: Some microstructural aspects of strength variation in rocks, Int. J. Rock Mech. Min. Sci., 2001, 38(5), 671-682 DOI: 10.1016/S13651609(01)00031-4

[7] Rajpurohit, S. S.; Sinha, R. K.; Sen, P.: Influence of Cerchar hardness index of hard rock granite on wear of diamond tools, Mater. Today Proc., 2020, 33, 5471-5475 DOI: 10.1016/j.matpr.2020.03.273

[8] Delgado, N. S.; Rodriguez-Rey, A.; del Ríó, L. M. S.; Sarriá, I. D.; Calleja, L.; de Argandoña, V. G. R.: The influence of rock microhardness on the sawability of Pink Porrino granite (Spain), Int. J. Rock Mech. Min. Sci., 2005, 42(1), 161-166 DOI: 10.1016/j.ijrmms.2004.08.010

[9] Dong, P.; Zhang, J.; Ouyang, C., Sun, D.; Wu, J.: Investigation on sawing performance of diamond frame saw based on reciprocating swing in processing hard stone, J. Mater. Process. Technol., 2021, 295, 117171 DOI: 10.1016/j.jmatprotec.2021.117171

[10] Yilmaz, N. G.: Abrasivity assessment of granitic building stones in relation to diamond tool wear rate using mineralogy-based rock hardness indexes, Rock Mech. Rock Eng., 2011, 44(6), 725-733 DOI: 10.1007/s00603-011-0166-1

[11] Yılmaz,N. G.; Goktan, R. M.; Kibici, Y.: An investigation of the petrographic and physico-mechanical properties of true granites influencing diamond tool wear performance, and development of a new wear index, Wear, 2011, 271(5-6), 960-969 DOI: 10.1016/j.wear.2011.04.007

[12] Li, Q.; Li, J.; Duan, L.; Tan, S.: Prediction of rock abrasivity and hardness from mineral composition, Int. J. Rock Mech. Min. Sci., 2021, 140, 104658, DOI: 10.1016/j.ijrmms.2021.104658

[13] Bulut, B.; Gunduz, O.; Baydogan, M.; Kayali, E. S.: Determination of matrix composition for diamond cutting tools according to the hardness and abrasivity properties of rocks to be cut, Int. J. Refract. Met. Hard Mater., 2021, 95, 105466 DOI: 10.1016/j.jijmhm.2020.105466

[14] Gupta, R. K.; Pratap, B.: Diamond tools processing for marble and granite: Cutting \& wear, Mater. Today Proc., 2021, 46(6), 2135-2140 DOI: 10.1016/j.matpr.2021.02.346

[15] Yan, G.; Yue, W.; Meng, D.; Lin, F.; Wu, Z.; Wang, C.: Wear performances and mechanisms of ultrahard polycrystalline diamond composite material grinded against granite, Int. J. Refract. Met. Hard Mater., 2016, 54, 46-53 DOI: 10.1016/j.ijrmhm.2015.07.014

[16] Adebayo, B.; Okewale, I. A.: Analysis of the potential of some Nigerian rocks to wear drill bit, $A U$ J. Technol., 2007, 11(2) https://www.thaiscience.info/journals/Article/AUJT/10290645.pdf

[17] Hardness, [Online]. Available: https://www.tf.unikiel.de/matwis/amat/mw1_ge/kap_8/advanced/t8_4_2.html

[18] Yusupov, T. S.; Kirillova, E. A.; Shumskaya, L. G.: Mineral hardness effect on the combined mineral 
grinding. J. Min. Sci., 2007, 43(4), 450-454 DOI: 10.1007/s10913-007-0046-y

[19] Xie, J.; Tamaki, J.: Parameterization of microhardness distribution in granite related to abrasive machining performance, J. Mater. Process. Tech., 2007, 186(1-3), 253-258 DOI: 10.1016/j.jmatprotec.2006.12.041 